DOI 10.37882/2223-2982.2020.11.29

\title{
СОПОСТАВИТЕЛЬНОЕ ИССЛЕДОВАНИЕ КОНЦЕПТУАЛЬНЫХ МЕТАФОР СО СФЕРОЙ-ИСТОЧНИКОМ «НЕЖИВАЯ ПРИРОДА» В ПОЛИТИЧЕСКОМ ДИСКУРСЕ СМИ РОССИИ И КИТАЯ (КОНЦЕПТОСФЕРА «ЗЕМНОЙ ШАР»)
}

\begin{abstract}
A COMPARATIVE STUDY OF CONCEPTUAL METAPHORS WITH THE SPHERE-SOURCE "UNLIVING NATURE" IN THE POLITICAL DISCOURSE OF THE RUSSIAN AND CHINA MEDIA (THE CONCEPTOSPHERE "EARTH")

A. Nekrasova O. Belyaeva
\end{abstract}

Summary: This article is devoted to a comparative cognitive study of metaphors with the source sphere «unliving nature», functioning in the Russian and Chinese political discourse of the media. In this work, an attempt is made to generalize the complex theory of metaphor in order to explore the specifics of the metaphorical representation of the political space in the political discourse of the media in Russia and China.

Keywords: political discourse; conceptual metaphor; unliving nature; frame.

\section{Введение}

ए лобализация проявляется во всех сферах жизни общества, и такая тенденция сохраняется в процессе интеграции и взаимодействия между национальными картинами политического мира, представляющими собой процесс и результат отражения в языке исторического, культурного, социального, языкового опыта определенного национально-лингвокультурного сообщества. Их можно найти в соответствующей системе концептуальных метафор. Древние ораторы полагают, что в процессе убеждения, не только нужны логически связанные аргументы, но и эмоциональное и психологическое воздействие на адресата также важны. Это особенно верно в политической коммуникации. Для политиков и авторов публицистических произведений одним из наиболее общедоступных приемов является метафора, стремящаяся создать яркие и запоминающиеся образы. Метафоры, используемые в текстах современных средств массовой информации, являются не столько приемами художественного отображения реальной действительности, сколько средствами создания определенной концептуальной системы, отражающей авторские интенции. Такая концептуальная система, будучи широко растиражированной, будет оказывать не-
Некрасова Александра Игоревна

Преподаватель, ФГБОУВО «Тихоокеанский государственный университет», Хабаровск

010290@pnu.edu.ru

Беляева Олеся Николаевна

Старший преподаватель, ФГБОУ ВО «Тихоокеанский государственный университет», Хабаровск

003835@pnu.edu.ru

Аннотация: Данная статья посвящена сопоставительному когнитивному исследованию метафор со сферой-источником «неживая природа», функционирующих в российском и китайском политическом дискурсе СМИ. В данной работе предпринята попытка обобщить сложную теорию метафоры для того, чтобы исследовать специфику метафорической репрезентации политического пространства в политическом дискурсе СМИ России и Китая.

Ключевые слова: политический дискурс; концептуальная метафора; неживая природа; фрейм.

сомненное воздействие на мировосприятие и мировоззрение читателей. [1.]

Актуальность данной статьи связана с необходимостью дальнейшего изучения закономерностей метафорического моделирования в современном политическом дискурсе СМИ. Сопоставительное изучение политических метафор в Китае и России способствует лучшему понятию специфики национальной картины мира, направлено на развитие межкультурного толерантности и содействие лучшему пониманию между народами двух стран.

Объект исследования - метафоры со сферой-источником «неживая природа», актуализированные в российском и китайском политическом дискурсе СМИ.

Предмет исследования - общие и специфические закономерности метафорической репрезентации политической действительности в текстах политической направленности, опубликованных в СМИ России и Китая.

Материалом для анализа в настоящей статье послужили посвященные политическим проблемам тексты, опубликованные в периодических изданиях России и 
Китая в интернете. Предпочтение отдавалось имеющим высокий тираж электронной версии газет и журналов, адресованным как специалистам, так и массовому читателю («Век», «Версия», «Завтра», «Коммерсант власть», «Континент», «Новая газета», «Новое время», «Общая газета», «РИА новости», «Комсомольская правда» 《新华网》，《人民日报》，《凤凰网》，《新浪新闻》，《搜狐新 闻》，《网易新闻》и др.).

Основная цель настоящей статьи - выявление общих закономерностей и национальных особенностей метафорических моделей со сферой-источником «неживая природа», используемых в современных СМИ России и Китая для создания образа политической действительности.

Достижение указанной цели предполагало решение следующих задач:

1) поиск, отбор и систематизация русского и китайского текстовых материалов, в том числе концептуальные метафоры, принадлежащие к «неживой природе», как сфере-источнику метафорической экспансии;

2) выделение, сопоставительное описание и классификация ведущих метафорических моделей сферы-источника, используемых в современных русских и китайских политических текстах СМИ;

3) обобщать результаты сопоставительного анализа закономерностей метафоризации политической действительности в политическом дискурсе СМИ России и Китая

Методологией данного исследования послужили научные труды в области теории метафорического моделирования (Ю.Н. Караулов, А.Н. Баранов, С.Л. Мишланова, Т.Г. Скребцова, Э.В. Будаев, А.П. Чудинов, И.М. Кобозева, Е.С. Кубрякова, Ю.Б. Феденева, Е.И. Шейгал, Lakoff); в области изучения регулярности семантических преобразований (Ю.Д. Апресян, Н.Д. Арутюнова, О.П. Ермакова, Е.А. Земская, Л.А. Новиков, Г.Н. Скляревская, И.А. Стернин, Е.И. Шейгал, Д.Н. Шмелев и др.) и другие направления лингвистики, связанные с изучением дискурса (В.И. Карасик 2004; Е.С. Кубрякова 2004; М. Макаров 2003; Ю.Е. Прохоров 2004), в том числе политический дискурс (В.Н. Базылев, А.Н. Баранов, Т. Ван Дейк, Э.В. Будаев, В. З. Демьянков, Е.И. Шейгал, А.П. Чудинов).

Основные методы исследования - дискурсивный анализ, когнитивное исследование. При обобщении, систематизации и интерпретации результатов наблюдений применялся описательный метод. Кроме того, были использованы элементы контекстуального и количественного методов анализа, а также общенаучные методы наблюдения, обобщения и сопоставления.

Теоретическая значимость исследования состо- ит в том, что выявлены доминантные метафорические модели со сферой-источником «неживая природа», которые включают фреймы и слоты и функционируют в современном политическом дискурсе СМИ России и Китая, и раскрыта связь между активностью метафорической модели и природы в определенном периоде. Материалы исследования могут быть использованы при дальнейшем развитии теории метафорического моделирования и при сопоставительном лингвокультурологическом изучении национальных картин политической реальности, а также при изучении закономерностей метафорического моделирования в других дискурсов, других языков и культур.

Научная новизна заключается в выделении, сопоставительном описание и классификации метафорических моделей со сферой-источником «Неживая природа». Эти модели метафоры актуализируются в Российском и Китайском политическом дискурсе СМИ, тоже заключается в выявлении закономерностей, регулирующего использования этих моделей в целях повышения целостности и выразительности высказывания; также заключается в свидетельстве как о национальном своеобразии российской и китайской метафорической картины политической реальности, так и об общих направлениях в развитии международного политического дискурса.

Практическая ценность определяется возможностью использования результатов исследования и его материалов процессе составления словарей, в практике двуязычной лексикографии, в процессе преподавания иностранного языка студентам (особенно тем, кто изучают два иностранных языка), а также в теории и практике перевода.

В настоящей статье были проанализированы только фреймы с наибольшим числом метафорических единиц, отобранных в ходе анализа.

Проведенный анализ отобранных метафорических единиц позволил выделить следующую основную метафору с исходной понятийной сферой «Земля». Внутри данной концептосферы были выделены следующие фреймы:

1) «рельеф» - утес, обрыв, пропасть, яма, пик, гора и т.п. Данная группа является многочисленной по составу и репрезентует образ либо возвышенности, либо падения. Использование таких метафор в высказываниях политиков может показать риск политических действий. Например, метафора, содержащая в себе образ «утес» распространена не только в русских стихотворениях, но и в политических текстах:

Если лидер КПРФ Зюганов - это утес-великан, то 
влажный след на его могучей груди оставлен «золотой кучкой» Семигиным. [2.]

«Утес» - образ сильного, могучего человека, обладающего настоящей душой, способного к искреннему чувству и переживанию.

Я уже говорил о том, что если пик не пройден, то достигнут, я так аккуратненько скажу. [3.]

Метафора «пик» обладает значением предела, самой высокой точки места. Общее метафорическое значение - кульминация.

从革命斗争的这种失误教训中，毛泽东同志深刻认识 到，面对中国的特殊国情，面对压在中国人民头上的三 座大山.

В китайском языке для обозначения трудностей или препятствий употребляются метафоры со словом 山 (гора). Данный образ воспринимается как образ чего-то труднопреодолимого, в связи с тем, что гора имеет внушительные размеры.

2) «почва» - почва, болото и т.п. Трудно переоценить значение почвы - это уникальное творение природы: именно она связана с жизненными интересами народа. Почва дает растениям, животным и людям жизни. Она главные богатства и объект поклонения всех земледельческих народов. Таким образом, в древней цивилизации люди считают огонь, воздух и вода наряду с почвой (иногда деревом и металлом) одним из краеугольных камней Вселенной, а также материнским начало.

Кроме того, это один из поводов внутрикорпоративных конфликтов, которые проходят скрытно или выплескиваются на слушателей и зрителей. Но это питательная почва для произвола чиновников. [4.]

Посредством сравнительного анализа примеров, можно сказать, что более характерно для китайских публикаций то, что метафора группы «почва» олицетворяет политическую ситуацию. Политики, как агрономы и землепашцы, они часто берегут политическую почву, терпеливо ждут урожая, то есть результаты их деятельности. А в китайской языковой политической ситуации характерно то, что метафора почвы сочетается с коррупцией.

但是，我们清醒地认识到，滋生腐败的土壤依然存 在，反腐败形势依然严峻复杂。从实际情况看，影响反 腐败成效的问题主要是，反腐败机构职能分散、形不成 合力，有些案件难以坚决查办，腐败案件频发却责任追 究不够。解决存在的问题，必须依靠改革和制度创新。

В китайском языке особенно выделяется образ болота. Оттого что болото тесно связано со смыслом грязи, оно находится на границе концептов земли и воды. Болото затрудняет выход из сложившейся ситуаций.
三四线城市楼市陷入泥潭，而一线城市却火热得不得 了，楼市已经不正常了。市场总是难以捉摸，楼市尤其 如此。 (Перевод: Рынок недвижимости в городах третьего и четвертого эшелонов находится в трясине...)

3) «стихийные бедствия» - землетрясение, извержение вулкана, лавина, обвал, пожар.

Политические, финансовые, экономические, и социалистические события выражаются сферой стихийные бедствия, как непредсказуемые и губительные стихийные бедствия.

Женщине сверху пришлось наблюдать жуткую картину, как стихия сносит дома, как тонет скот. [5.]

《经济通通讯社记者伍嘉仪4日报道》汇业财经集 团主席区宗杰接受《经济通通讯社》专访时，分享对全 球经济的看法。「我们正迈向金融海啸，而将来的整体 环境可能比2003年沙土时期及 2008 年金融海啸 ( иунами ) 更差。 (Перевод: Мы идем навстречу финансовому цунами....)

О землетрясении знают все, даже те, кто живет далеко от опасных регионов. Землетрясение - это подземные толчки и колебания земной поверхности.

Для дискурса СМИ сила в баллах землетрясения не является объектом метафоризации. Развитие землетрясения может разделяться различными этапами. Именно начало землетрясения, процесс землетрясения, и его результат. А различные этапы формируют метафоры как собственные когнитивные динамические сценария.

Однако в метафорическом выражение в СМИ, в том числе подземный гул, глухие подземные толчки, вздрагивать и так далее, в метафоризации осуществляется смысл неявный, предшествующий чему-то главному. Среди них обозначение концепта - предвестие социальных потрясений выделяется и остается самым распространенным.

Российская армия решила все проблемы и продолжает наращивать свою мощь. [6.]

新赛制震动 ( вздрогнуло) 中国体操。已经有消息表 明，在下届东京奥运会上，体操团体项目的赛制将再次 做出巨大的改变，参加团体项目的参赛人数将由现在的 五名减少到四名，而这种改变给中国体操队带来的挑战 无疑是巨大的。

В примере в русском и китайском языке используют метафоризации вздрогнуть, у которого осуществляется переносное значение: от дрожания чего-то до оказывания влияния чего-либо, от видного действия превращается в невидное влияние.

В общем в китайском языке больше глаголов, связанные с иероглифом 动(движение), 感动 ( растрогать) 
、震动 ( трясти)、振动 ( колебаться) и др., они соответсвуются с русскими метафорами. Сравнивая эти метафоры, можно прийти к выводу, что они осуществляют перемену от конкретного действия к абстрактному воздействию.

Метафора актуализируется обычно с помощью использования таких источников: трясет, эпицентр, землетрясение и также социальное потрясение, в китайском языке 地震(землетрясение)，震 ( сотрясение)，社会震 荡 (социальное потрясение). Денотат выражения такого типа метафоры- непредсказуемое поведение видных политиков и финансистов. В этом случае метафоризация происходит в следующих значений: быстроты протекания и непредсказуемости, разрушительности.

В главной оппозиционной партии Франции «Союз в поддержку народного движения» (СПНД) продолжается политическое землетрясение. [7.]

2013年6月23日凌晨3时，38岁的江西省新干县原副 县长刘建军在广东省珠海市一酒店被公安机关抓获。随 后，曹正光（吉林白山市人）、苏铁（苏荣之子）相继 被调查，江西官场地震 (землетрясение)的序幕被拉开 了。

Политическое разочарование, свержение старых идеалов общества получило определенное социальное потрясение в дискурсе СМИ.

Советская власть стояла на прочном основании и до поры до времени реализовывала идеалы многих людей. Поэтому долго и продержалась - челых 70 лет. Почему она так быстро пала - эту загадку еще предстоит разгадать. Впрочем, в маситабах истории человечества само по себе "социальное потрясение» - нормальный общественный прочесс. Он случается сплошь и рядом. [8.]

尽管如此，就整体而言，2016年世界经济与政治中 最突出的特征应该还是新兴市场经济社会震荡深化扩 大。

Последствие землетрясения является тектоническим перемещением. Разломы-сплющенные разрушение горных пород в результате движений земной коры. Характеризуя смещение, разрушение старого и становление государств, и данный слот приобретает позитивную окраску.

Окончание холодной войны вызвало тектонический сдвиг на Африканском континенте. Утратив важнейшее геополитическое значение как поле соперничества между сверхдержавами и потеряв внешние источники финансирования. [9.]

Так, мы приводим к выводу, что слот землетрясение формирует следующие смыслы: из-за недовольства общества происходит какое-то событие в обществе, что оказывает серьезное влияние на общество.
Некоторые метафорические словоупотребления соотносят современную политическую ситуацию в стране с деятельностью вулкана: просыпающий вулкан, мощный выплеск, лава, горячий пепел, огнедышащее жерло и др. [10.]

Вулкан - коническая гора, и вершине ее кратер, через который из недр земли времени от времени извергается огонь, пепел, горячие газы, пары воды и пороки пород. Концепт, получившие метафорическое обозначение в этой сфере.

Политика, - народное возмущение, мощное проявление недовольства, террора и преступности. [10.]

«Регион сейчас напоминает политический вулкан, $и$ скандалы, связанные с местными элитами, - яркий признак этой нестабильности, - отмечает политолог Юрий Москвич. - При этом негативная информация, которая постоянно появляется в массмедиа, на берегах Енисея не становится поводом для каких-то громких уличных акций. [11.]

В этом случае метафоризация характеризуется несколькими смысловыми компонентами: опасность, сокрушительная сила и др.

Примирившись с судьбой, человеческая лава тихотихо начинает терять температуру кипения, успокаивается, затихает. [12.]

Метафорическое политическое и социальное проявление в стране как извержение вулкана, моделирует действительность агрессивности и опасности: недовольство народов и разгул преступности достигается таких размеров, и нельзя остановить их, они разрушают и сметут все препятствия на своем пути. Формируемые у читателя прагматические смыслы, способные вызывать негативные и эмоциональные влияния на адресата провоцированием в нем состояния тревоги и опасности. К сожалению, метафора со слотом «извержение вулкана» отсутствует в китайском языке.

Источниками метафорической экспансии являются такие концепты исходной сферы, как 崩塌 ( обвалиться), 崩陷 ( обрушиться), 倒塌 (рухнуть) в китайском языке, лавина, снежная лавина, лавинообразный, обвал, ледовый обвал, обрушиться. [13.]

Лавина земли и льда, снега, эти концепты может извергаться со склонов и разрушают все препятствия на пути. В политическом дискурсе обычно это имеет переносное значение: какая-то разрушительная сила ведет к неприятному последствию.

Труд Кейса Вааймана едва уместился в двух томах, 
и он разительно отличается от того необъятного, лавинообразного потока литературы на духовные и околодуховные темы, которая удручает угрожающей поверхностностью редукций и грубых компиляций. [14.]

从急速崛起到快速崩塌国民老公宁泽涛 $\mathrm{B}$ 面让人惊 讶。从一个众人喜爱的高情商、高颜值的明星运动员， 到游走于体育和娱乐、道德和任性的边缘，宁泽涛的急 速崛起和坍塌的过程让人惊讶，又让人迷茫甚至费解。

Значение быстрого ухудшения ситуации и изменение положения актуализируется с помощью использования концепта «обвал» или «обломки скал».

Обвал юаня принесет проблемы и КНР, и РФ, которая переходит с Китаем на взаиморасчеты в национальных валютах. [12.]

Экономическая и финансовая и даже нравственная сфера является частотным употреблением в этом процессе метафоризации. Можно понять, что финансовый кризис, банкротство метафорически осмысляются как лавина и обвал. А в этих случаях приватизация, ваучеризция и необдуманные решения служат причинами их возникновения.

Лавина экономических санкций против России является наглядным примером таких действий. Разумеется, эти санкции способны нанести значительный ущерб российской экономике. [12.]

央行公布7月金融数据，7月新增信贷和货币呈现雪崩 (обвал)状态。公开资料显示，7月广义货币M2同比增长 $10.2 \%$ 。当月人民币贷款增加 4636 亿元，贷款增速分别 比上月末和去年同期低 1.4 个和 2.6 个百分点，而6月人民 币贷款增加1.38万亿元，同比少增1.01万亿元。(2016 y Минь В первой половине года расходы страховых компаний на компенсацию увеличились на 25\% по сравнению с аналогичным периодом прошлого года, чтобы задействовать потенциал страховой помощи при стихийных бедствиях.)

Таким образом, в такой метафоризации с источниками 雪崩，崩溃 (крушение) , обвал, лавина, обычно проявляется какой-то непредсказуемое и опасное событие.

Источником метафоризации являются концепты разжечь, раздуть, задымиться, пламя, огонь, млеть, гореть и др., соответственно в китайском языке 火焰 (огонь)，燃 烧 (гореть)，点燃 (зажигать)，火，等等. [8.]

Самый главный концепт в этом слоте-пламя, которое может разрушать все и имеет почти самую большую разрушительную силу. Пламя может пригодиться людям, также может создавать опасность. Поэтому в этом слоте акцентируют значение тревожности, опасности и не- предсказуемых сокрушительных последствий.

Использование данного слота главным образом нужно для того, чтобы выразить значение бурного проявления чего-нибудь, как реформа, революция, и конфликт, война и т.д. Они имеют общие характеристики с очень большими разрушениями. Например:

Фоновые знания, формируемые в стране событиями и трагедиями, становятся основой в восприятии концепта и требуют развертывания метафоры в тексте.

Почему мы не верим, что страна тлеет, как торфяник? Почему мы убеждены, что все само собой устроится? Почему, явственно видя разделение России на выродившуюся элиту и обреченное, всех прав лишенное большинство, мы вспоминаем о катастрофичности происходящего, только когда этот потаенной огонь вырывается наружу? Ведь уже не тлеет. Уже - горит. [14.]

А в китайском языке особенно выделяется один тип использования 火(пламя), который может символизировать расцвет чего-то.

17日，一张温暖的照片刷爆网络：在漆黑的路上， 一名男子骑着三轮车，三轮车后面载着一个头发花白的 老人，一辆警车打开了大灯缓慢前行，为三轮车照亮回 家的路。人民日报微博转发这张照片，截至昨天下午4 点，已获得18300个转帖，12.5万个赞，阅读量超过1400 万。就如一位网友所说，“你们不仅照亮了回家的路，也 温暖了这个寒冷的冬天。”网友随手一拍，让这辆警车火 (пламя)了.

\section{Результаты}

Так, в большинстве моделей метафорических словоупотреблений, общественные потрясения - это стихийные бедствия. Характеризуя политическую, социальную экономическую и финансовую сферу, несут явно выраженный негативный прагматический смысл. Они создают образ опасной и непредсказуемой действительности. В такой ситуации выжить и противостоять происходящим процессам практически невозможно.

Данные количественного анализа позволяют утверждать, что самой продуктивной сферой-источником метафоризации действительности в обоих языках стала концептосфера «земной шар», к которой были отнесли 65 метафор из российских дискурсов и 47 - из китайских публикаций, что составляет около двух третьей всех исследованных словоупотреблений. В процессе исполнения политических целей формируются политические иерархия, в которых высокопоставленные кадры находятся на высшем месте. А для указания политических причин или начала каких-то событий, китайцы предпочитают использовать метафоры фрейма почвы, а русские фреймы недра-земли. 


\begin{tabular}{|l|c|c|}
\hline \multicolumn{1}{|c|}{$\begin{array}{c}\text { Концептуальные элементы понятийной } \\
\text { сферы «Неживая природа» (фреймы) }\end{array}$} & СМИ России & СМИ Китая \\
\hline РЕЛЬЕФ & $4(3.8 \%)$ & $3(4.2 \%)$ \\
\hline ПОЧВА & $2(1.9 \%)$ & $3(4,2 \%)$ \\
\hline СТИХИЙНЫЕ БЕДСТВИЯ & $13(12.5 \%)$ & $10(14 \%)$ \\
\hline ВРЕМЯ ГОДА & $4(3.8 \%)$ & $3(4.2 \%)$ \\
\hline ВСЕГО & $106(100 \%)$ & $72(100 \%)$ \\
\hline
\end{tabular}

\section{ЛИТЕРАТУРА}

1. Тупицына Ирина Николаевна, Скороходова Елена Юрьевна. [Электронный ресурс]: Природа метафоры и ее использование в современной российской прессе // Вестник ЧелГУ. 2009. №22. Режим доступа: https://cyberleninka.ru/article/n/priroda-metafory-i-ee-ispolzovanie-v-sovremennoy-rossiyskoy-presse (дата обращения: 22.09.2020)

2. Проханов А., Ночевала тучка золотая... [Текст] / А. Проханов // «Завтра». - 2002. - № 4. - с. 9.

3. Выступление Владимира Путина на инвестфоруме «Россия зовет!». Онлайн-трансляция. [Электронный ресурс]: ТАСС, 13 октября 2015 год. Режим доступа: https://tass.ru/ekonomika/2341304 (дата обращения: 12.09.2020)

4. Новости дня. [Электронный ресурс]: РИА Новости, 18.06.2020. Режим доступа: https://ria.ru/20020618/176334.html (дата 0бращения: 12.09.2020)

5. Партия «Республиканцы». [Электронный ресурс]: РИА Новости, 11.06.2017. Режим доступа: https://ria.ru/20170611/1496099219.html (дата обращения: 15.09.2020)

6. П.С.Гуревич. [Электронный ресурс]: Феном социальных потрясений. Режим доступа :https://iphras.ru/uplfile/histan/kruglye_stoly_pdf/fenomen_ sotsialwnyh_iotryaseniy.pdf (дата обращения:15.09.2020)

7. Борисов Д.И. Китайские решения африканских проблем. [Электронный ресурс]: Независимая газета, 2.11.2015. Режим доступа: https://www.ng.ru/ courier/2015-11-02/10_africa.html (дата обращения: 2.09.2020)

8. Чудакова Н. М. Метафоры из сферы-источника «Природа» в современных СМИ // Речевая культура в разных сферах общения: Сборник статей сотрудников проблемной лаборатории «Речевая культура в разных сферах общения». Выпуск 1 / Сост. Т. С. Кириллова, Г. А. Авдеева. Нижний Тагил, 2003. C. $64-72$.

9. Чернявский А. Красноярский политический вулкан [Электронный ресурс]: Независимая газета, 18.02.2014. Режим доступа: https://www.ng.ru/ng_ politics/2014-02-18/13_krasnoyarsk.html (дата обращения: 3.09.2020)

10. Харабадзе Г. Опасные гастроли советского грузина. [Электронный ресурс]: Новая газета, 18.03.2004. Режим доступа: https://novayagazeta.ru/ articles/2004/03/18/22695-georgiy-harabadze-opasnye-gastroli-sovetskogo-gruzina (дата обращения: 6.09.2020)

11. Стародубцева Л.В. Научный путеводитель по лабиринтам духовности. [Электронный ресурс]: Независимая газета, 25.09.2009. Режим доступа: https:// www.ng.ru/ng_religii/2009-05-20/7_Spirituality.html?id_user=Ү(дата обращения: 9.09.2020)

12. Юань приблизился к обвалу. [Электронный ресурс]: Рамблер/Финансы. Режим доступа: https://finance.rambler.ru/economics/31868541-yuan-priblizilsyak-obvalu/ (дата обращения: 3.09.2020)

13. Андрей Гамалов // «Консерватор», №13, 11-17 апреля 2003 года. [Электронный ресурс]: LiveJournal. Режим доступа: https://ru-bykov.livejournal. com/3176910.html (дата обращения: 4.09.2020) 